\title{
Fazer a teoria do cinema a partir de cineastas - entrevista com Manuela Penafria
}

\author{
Bruno Leites \\ Doutor; Universidade Federal do Rio Grande do Sul, UFRGS, RS, Brasil \\ bruno.leites@ufrgs.br
}

\section{Eduardo Baggio}

Doutor; Universidade Estadual do Paraná, UNESPAR, PR, Brasil

baggioeduardo@gmail.com

\section{Marcelo Carvalho}

Doutor; Universidade Tuiuti do Paraná, UTP, PR, Brasil

marcelocarvalho.0001@yahoo.com.br

\section{Resumo}

Nesta entrevista, a pesquisadora e professora Manuela Penafria (Universidade da Beira Interior, Portugal) expõe o cenário atual da abordagem Teoria dos Cineastas, destacando a pertinência de renovar a teoria do cinema a partir do pensamento expresso nas imagens, nos sons e nas palavras de cineastas. Penafria discute uma série de temas relevantes à pesquisa e à teorização em cinema, tais como: as fontes de pesquisa; a diferença entre a palavra e a imagem na Teoria dos Cineastas; a relação da Teoria dos Cineastas com a pesquisa de Jacques Aumont sobre as teorias dos cineastas; o conceito de espectador que circula entre cineastas; e a suspeição que pode surgir no meio acadêmico com relação à Teoria dos Cineastas.

\section{Palavras-chave}

Teoria dos cineastas. Teoria do cinema. Espectador. Jacques Aumont. Filme-ensaio.

Partindo da constatação de que a pesquisa em cinema andava, em certa medida, afastada do pensamento de cineastas, Manuela Penafria movimentou uma rede de pesquisadores para dedicar-se à Teoria dos Cineastas. Esta rede, atualmente, reúne-se em 
torno do GT Teoria dos Cineastas da AIM e do ST Teoria dos Cineastas, da Socine, o primeiro em atividade desde 2015 e o segundo desde 2016.

Além das investigações com a abordagem Teoria dos Cineastas, Manuela Penafria possui uma trajetória de pesquisa no campo do documentário, tendo publicado o livro $O$ Paradigma do Documentário: António Campos, Cineasta (2009) e editado Tradição e Reflexões: Contributos para a teoria e estética do documentário (2011), além de uma série de artigos e capítulos de livros sobre o tema.

No campo da Teoria dos Cineastas, editou os livros Ver, ouvir e ler os cineastas: Teoria dos Cineastas v.1 (2016); Propostas para a teoria do cinema: Teoria dos Cineastas v.2 (2016) e Revisitar a teoria do cinema: Teoria dos Cineastas v.3 (2017).

Suas preocupações direcionam-se para os aspectos metodológicos desta abordagem e para o conceito de espectador que circula entre cineastas. Como destaca Penafria nesta entrevista, a abordagem Teoria dos Cineastas deve se preocupar em constituir e renovar a teoria do cinema, tomando como fonte primária as imagens, os sons e as palavras de cineastas. Dessa forma, a Teoria dos Cineastas não se preocuparia com a teorização de cineastas sobre temas em geral, mas sobre o próprio cinema e sua inserção no mundo.

A entrevista foi realizada em junho de 2019 com a presença de Eduardo Baggio em Covilhã, Portugal, na Universidade da Beira Interior, instituição onde Penafria atua. Os demais entrevistadores participaram via dispositivo de chamada online.

\section{Vamos começar com uma parte difícil pela amplitude. 0 que é Teoria dos Cineastas e quem são os cineastas citados no nome desta abordagem teórica?}

Eu vou, então, começar pela parte mais fácil. Os cineastas mencionados na proposta são todos os que contribuem e que, efetivamente, fazem filmes, independentemente de qual seja a função. Agora, a questão da Teoria dos Cineastas induz um pouco em erro, no imediato. Porque desta forma parece que os cineastas todos têm uma teoria, não é? Eu não sei se têm, a questão não é esta, a questão é: para a academia estudar cinema esta é uma abordagem 
que pode, efetivamente, tanto alargar os temas a serem investigados, como promover um retorno aos grandes cineastas. A Teoria dos Cineastas obriga-nos a ter uma relação direta com quem faz cinema e eu acho que esta é a grande mais valia da proposta. E isto para quê? Para se fazer teoria do cinema. Portanto, a questão não passa por querermos fazer a teoria do cineasta, porque o cineasta não precisa do acadêmico pra nada, não precisa. Vai continuar a fazer seus filmes e não precisa do acadêmico. E ele também não precisa que estejamos a organizar o pensamento dele. Isso era chamá-lo de incompetente, algo que os cineastas não são. Trata-se, portanto, de a academia pensar o cinema colocando-se ao lado do cineasta, olhando para o cinema a partir de quem faz cinema. E, justamente, para compreendermos melhor o cinema temos que nos posicionar ao lado do cineasta. Eu posso dar o exemplo do trabalho que fiz recentemente sobre a Noémia Delgado. Eu adotei a abordagem da Teoria dos Cineastas e fiz um recolha das entrevistas que ela fez aos cineastas portugueses Faria de Almeida e António de Macedo. 0 que é interessante é que estas duas entrevistas revelam muito do seu pensamento, da sua concepção de cinema. E nas entrevistas que deu, ela falou muito sobre filmes que nunca tinha feito. Eu não tinha previsto isso inicialmente, mas quando cheguei no final dei-me conta do fato de que a quantidade de filmes que ela nunca fez era grande. Eu encontrei no mínimo cinco, e cinco já é um número de filmes bastante relevante. E, nesse sentido, a noção de filmografia passou a ser não apenas os filmes feitos, mas os filmes que também ficaram por fazer.

\section{Você estabeleceria alguma hierarquia entre as fontes de pesquisa?}

\section{Algumas seriam mais importantes do que outras?}

Não, acho que não, porque em qualquer momento nós podemos encontrar um material que não havíamos pensado encontrar. Um exemplo. Em minha tese de doutoramento já trabalhava com a Teoria dos Cineastas sem ter consciência disso. Eu fiz um levantamento de todas as entrevistas que o António Campos concedeu, trabalhei muito a partir das entrevistas (este trabalho sobre o António Campos foi a parte da tese que eu publiquei). Nessa busca, encontrei um depoimento dele, nem era uma entrevista mesmo, era única e exclusivamente um depoimento que ele tinha dado para um jornal a respeito da exibição de um dos seus primeiros filmes, de 1957, 1958. Nesse depoimento é que encontrei 
a expressão "poesia com os pés na terra". Foi a partir dessa expressão que começou a fazerme sentido toda a filmografia dele. Isso para dizer que acho que não vale a pena considerar um material mais importante do que outro. Temos que estar sempre atentos, porque, às vezes, a mais pequena manifestação, o mais pequeno gesto pode ser inspirador.

\section{Nesta questão das fontes de pesquisa, repetidamente enfrentamos a diferença entre o material escrito e o material imagético. É difícil não nos referirmos à opção do Jacques Aumont (2004) pela pesquisa do material escrito.}

Todos os materiais de pesquisa são importantes do ponto de vista da investigação. Mas se for para escolher apenas um, escolho os materiais fílmicos. Se estamos a falar da Teoria dos Cineastas, se estamos a procurar o pensamento e a poética do cineasta, independentemente de ser ou de não ser teoria, isto estará nos filmes mais do que na escrita. 0 problema é que eu acho que nós não temos vocabulário para escrevermos sobre os filmes. Eu costumo dar um exemplo: aquela espécie de campo/contracampo de Ingmar Bergman em Persona (1966), como que se chama aquilo? Que nome é que damos àquilo? Não é propriamente um campo/contracampo. Falta-nos vocabulário ou temos que inventálo. São duas maneiras de pensar completamente distintas. A crítica literária utiliza a linguagem escrita para se referir às obras que também são escritas, e aí há uma paridade do ponto de vista de expressar uma ideia, de expressar pensamentos. Por outro lado, quando nós escrevemos sobre um filme, logo à partida há um desnível, nós estamos a utilizar a linguagem escrita para nos referirmos a uma obra que usa outra forma de pensamento. Mas há hoje um fenômeno interessantíssimo que são os ensaios audiovisuais. Eles utilizam o mesmo material dos filmes, as imagens e os sons, para falarem, para se relacionarem com os filmes. 
A imagem coloca uma ordem de desafios que são estranhos à escrita, uma sensorialidade exacerbada. No seu texto com Henrique Vilão e Tiago Ramiro (PENAFRIA; VILÃO; RAMIRO, 2016) tu ressaltas bastante a questão da experiência. O filme promove a experiência e a partir daí os pesquisadores vão propor conceitos?

Exato, mas eu acho que esta questão ainda não está resolvida. Como é que a abordagem Teoria dos Cineastas se confronta única e exclusivamente com filmes? Imagine uma hipótese radical, colocar de lado todo o discurso, todas as entrevistas, todos os textos escritos pelo cineasta. Ao final só temos os filmes. Mas a questão é que, novamente, há uma dificuldade enorme em termos de vocabulário para falarmos sobre filmes. 0 cinema é uma forma de pensamento. Eu não considero o filme um texto, é uma forma de pensamento, só é texto no sentido em que constrói a sua própria gramática. E, portanto, mostra-nos ligações entre coisas que nós nunca teríamos pensado antes se usássemos única e exclusivamente a linguagem escrita ou falada. E há a imagem, que nos dá outra possibilidade de construirmos uma linguagem, que nos obriga a pensar, a termos ideias que nunca teríamos se não fosse esse universo imagético.

Quando você fala do problema com o vocabulário, será que a gente não toca na questão da função do pesquisador, enfim, na relação que se estabelece a partir do material que ele encontra? Isso significa que o pesquisador seria aquele que formula conceitos a partir dos filmes, do pensamento do cineasta, não?

Sim. Nós temos um texto (PENAFRIA; BAGGIO; GRAÇA; ARAÚJO, 2017) em que há algo que me faz sentido: o cineasta sendo não apenas fonte de informação, mas também fonte de inspiração. A academia tem muito a ganhar se entender o cineasta como fonte de 
inspiração. Isto porque eu acho que em muitas teses de doutoramento há uma preocupação excessiva com a metodologia, sob o risco de não se avançar no pensamento sobre o cinema. E quando estou a falar do pensamento sobre o cinema, falo de uma construção mais livre em relação ao rigor metodológico que é imposto, em especial, pelos programas de doutoramento. Penso que assim se vai libertar o estudo sobre cinema para uma via em que a metodologia é muito parecida com aquilo que os filósofos fazem, que é construir sua própria metodologia e não estar obrigado a percorrer o caminho deste ou daquele modo. Porque se nós tivermos uma metodologia rigorosa e toda gente tiver que seguir por ali, bom, avançamos no conhecimento, mas não avançamos no pensamento sobre o cinema - o que é um retrocesso.

\section{A Manuela está fazendo, assim, uma aproximação incrível com a vontade dos críticos. A crítica gosta da ideia de que se deixe de lado certas metodologias tradicionais, e que se use a inspiração, que se atenha aos filmes, eventualmente até exclusivamente aos filmes. Também gosto muito desta ideia, mas há um ponto nevrálgico, difícil: como conciliar isso com os pressupostos científicos e acadêmicos?}

Há uma questão essencial a ser dita. Será que toda gente que faz investigação sobre cinema é efetivamente espectador de cinema? Isso é absolutamente fundamental. Nós não podemos fazer uma tese sobre cinema se não formos espectadores no sentido, se calhar, mais rigoroso, no sentido em que o cinema é a vida. Nós não estamos a tentar compreender o cinema com a Teoria dos Cineastas, nós estamos a tentar compreender a vida através do cinema. E para isso, temos que ser espectadores de cinema, antes de sermos investigadores, nós temos que ser espectadores de cinema como o crítico é. Pode depois elaborar um discurso que fique aquém do filme, estar ao serviço da confirmação dos seus próprios valores. E esta é outra questão absolutamente fundamental: o que é que eu vou buscar aos filmes? Vou buscar só aquilo que me interessa? Ou estou suficientemente aberta àquilo que o cineasta me está a dizer? 


\section{Mas é possível desenvolver esses pontos de vista levando-se em conta os pressupostos científicos?}

Eu acho que sim. Acredito na academia, eu sou uma académica. A academia é justamente isso: a possibilidade de produzirmos conhecimento e pensamento, inclusive a partir de metodologias novas, de posturas novas. Existe este espaço dentro da academia. Pode haver mais ou menos abertura para isso, mas este espaço obrigatoriamente existe.

\section{EB: creio que haja uma ligação entre o pesquisador como espectador e a inspiração. É uma questão de estabelecermos que tipo de relação construímos com os filmes.}

Exato. Veja a evolução da teoria do cinema. Nos anos 1970 era quase inadmissível fazer uma tese de doutoramento sobre cinema sem abordar a psicanálise. Há paradigmas de pensamento e, quanto à pesquisa em cinema, o que está em causa na submissão a um paradigma é uma determinada postura enquanto espectador. A questão de que espectadores nós somos é bastante lata em relação a toda teoria do cinema. A história da teoria do cinema inclui este ou aquele autor tendo em vista determinados tipos de espectadores. Isso também se relaciona com o discurso que é feito sobre os filmes, o discurso da crítica, o discurso académico. Isso é importante: o investigador é espectador, tem que ser espectador de cinema, tem que haver um confronto direto com a obra. Uma tese sobre cinema tem que mostrar um embate direto com os filmes, uma apreciação direta com os cineastas. Eu cheguei a ver teses de doutoramento que falavam sobre os filmes e não havia uma única linha em que a pessoa que fez a tese dissesse o que é que pensava diretamente sobre os filmes, ia sempre buscar uma citação. 
No terceiro volume da série de livros Teoria dos Cineastas, no capítulo “Observações sobre a 'Teoria dos Cineastas' - Nota dos Editores", está expresso um receio da academia com relação à Teoria dos Cineastas.

Isso ficou no texto porque Teoria dos Cineastas é uma expressão que não explica exatamente o que se pretende, isto é: fazer teoria do cinema a partir dos cineastas e do pensamento dos cineastas. Isso era demasiado longo para ficar no título. Então, ouvimos a crítica: "quem faz a teoria na academia é o académico e não o cineasta". Mas a ideia é justamente essa! Estamos a fazer teoria do cinema indo buscar um apoio - e a teoria do cinema sempre foi buscar apoio em algo exterior ao cinema - aos cineastas, àquilo que eles dizem e fazem.

\section{O pesquisador na Teoria dos Cineastas teria a função de formular o} vocabulário, formular conceitos que deem conta do universo fílmico. Mas poderíamos, em algum sentido, considerar a posição do pesquisador também como um mediador entre a obra do cineasta e outro tipo de universo e de linguagem (no caso, a linguagem escrita)?

Entender o investigador como mediador, não. Não se trata de traduzir aquilo que seria o pensamento do cineasta. 0 investigador, o académico, tem que produzir conhecimento, teoria do cinema. 0 pensamento do cineasta é tão forte quanto qualquer conhecimento produzido na academia, é nesse sentido. Então, não é mediação, mas criação. A questão é criar teoria do cinema colocando-se de uma maneira próxima a outro criador, do cineasta, que é um criador muito forte. Há um risco aqui: o investigador pode, muito facilmente, servir de transmissor do pensamento do cineasta. Isso seria um erro, seria não fazer teoria do cinema. 0 que é importante é fazer teoria do cinema que seja académica, que tenha validade na academia, e que seja diferente daquela que tem sido feita até há alguns anos, ou até hoje. 
Mas o investigador não tem que ser, em alguns casos, um sistematizador? Porque o cineasta que profere pensamentos sobre filmes sob outras formas que não fílmicas, não está preocupado em sistematizar, e a academia busca a sistematização, a organização de coisas que possam estar esparsas.

Mas esta sistematização já é da responsabilidade do investigador. E ao fazer essa sistematização ele também está a criar, pois está a produzir conhecimento. Jacques Aumont faz isso com relação a Tarkovski. Ele fala em três níveis diferentes de tempo, mas Tarkovski nunca disse isso. Aumont está aí a fazer teoria, está a sistematizar a partir do cineasta, e está a trabalhar dentro da academia. É a mesma coisa que compreender a teoria do cinema e o próprio cinema por via da psicanálise. 0 que se faz é retirar de lá aquilo com que o pesquisador sabe lidar, se calhar até, em algum momento, ele pode deturpar algum conceito, mas não é por este motivo que se coloca em causa a teoria do cinema feita a partir da psicanálise. Aqui é exatamente a mesma coisa. Acho que o real problema é que o pensamento do cineasta é tão interessante que ofusca - e deixa-nos este problema: o que é que eu posso acrescentar sobre seus filmes que ele já não tenha dito?

Mas se a sistematização se der sobre um campo mais determinável, seja sobre filmes ou em falas e textos dos cineastas, estaríamos ainda em um ato de criação ou em uma expressão mais objetiva, tipicamente científica? Por exemplo, numa investigação sobre como Joaquim Pedro de Andrade se expressava formalmente, com que frequência ele utilizava certos tipos de movimentos de câmera, de planos etc.

Mas isso é o que está no filme, pode-se contar quantos grandes planos lá existem. E temos que encontrar o mesmo número, certo? Agora, como é que nós organizamos esses elementos é outra coisa. Podemos construir sistematizações completamente distintas a 
partir dos mesmo dados e é neste sentido que me refiro ao ato de criação do investigador. Nós dois podemos fazer, cada qual, um doutoramento sobre Joaquim Pedro de Andrade e vamos dizer coisas distintas - e estamos a falar sobre o mesmo cineasta. Mas, se nós adotarmos a abordagem da Teoria dos Cineastas, mesmo que haja variações, nós estamos a colocar-nos dentro de um paradigma de pensamento e de um tipo de relação com o cinema. E a consequência é a academia fazer uma teoria do cinema distinta da que tem sido feita. Justamente, é a diferença entre "teoria" e "teorias", no singular e no plural: falamos de Teoria dos Cineastas e eu acho importante ressaltar esse singular para destacar que os cineastas têm um determinado modo de pensar. É claro, há uma diversidade enorme entre os cineastas, mas há ali um outro modo de pensar que é distinto do modo de pensar da academia.

\section{Este é um modo de pensar claramente diferente do objetivo do Jacques} Aumont quando ele propõe as teorias dos cineastas, porque o Aumont está apontando para cineastas que ele entende que tenham efetivamente formulado teorias.

Sim. No livro ele fez a opção por aqueles que escreveram sobre cinema. Foi uma opção naquele momento de fazer um livro a partir de materiais escritos. Mas ele não fecha a porta para, por exemplo, uma pesquisa que se dispusesse a estabelecer as teorias dos cineastas apenas considerando os filmes. Isso é até uma coisa que a Teoria dos Cineastas deveria fazer, deveria tentar ir só aos filmes, ou encontrar um cineasta que só tivesse feito filmes, que não tivesse escrito. 
Jacques Aumont não fecha a porta, mas ele demonstra uma espécie de receio. Diz que os filmes podem, no máximo, fazer atos de teoria, não exatamente teoria.

Eu entendo esse receio por algo muito simples. Jacques Aumont tem muito claro que quando nós acedemos a um filme, cada investigador acede de um modo diferente. Eu acho que é mais neste sentido. Porque com o texto escrito nós temos, digamos, o ponto de vista tradicional, nós temos mais capacidade de interpretação e de citação do texto escrito. Agora, a relação que o investigador tem com os filmes, se calhar, não tem uma tradição assim tão forte.

Tu achas necessário diferenciar pensamento de teoria? "Pensamento" ou "teoria" dos cineastas seriam termos equivalentes ou não?

Eu gostaria de complementar. O termo "pensamento" foi o que nós encontramos, mas também poderia ser "ideia", algo que sugerisse que nem todo cineasta teria uma "teoria". Mas, afinal de contas, o que é que nós estamos buscando com a Teoria dos Cineastas?

Reafirmo, o investigador tem de fazer a teoria. E a teoria é um pensamento organizado, sistematizado, coerente. A questão é que os cineastas que têm uma espécie de obsessão sobre aquilo que fazem - disso falou também o Jacques Aumont -, se calhar, organizam seu pensamento de uma maneira que está, digamos, dentro da categorização de teoria. E o investigador pode confrontar-se com esse pensamento mais ou menos sistematizado. Mas isso não quer dizer que um pensamento menos sistematizado seja um pensamento menor ou que não seja interessante. Um pensamento pode entrar no cânone do que se chama teoria, ou pode não entrar. E o que é que o investigador tem que fazer? Tem que se preocupar com a sua investigação do ponto de vista da criação de uma teoria do cinema. Não acho que tenha que estar preocupado se o cineasta tem um pensamento coerente ou não. 
Mas qual o risco que a abordagem Teoria dos Cineastas tem de passar a ideia de que bastaria ir ao cineasta, recolher alguns tipos de considerações e levá-las ao público?

$\mathrm{Eu}$, sinceramente, acho que não corre risco nenhum. Acho importantíssimo termos movimentos em relação aos cineastas ou, especificamente, termos, em algum momento, alguém que tenha feito uma recolha de materiais daquele cineasta.

Mas a Teoria dos Cineastas corre o risco de parar neste trabalho.

Eu acho que só há esse risco se as pessoas, de fato, entenderem mal a Teoria dos Cineastas. Achas que têm entendido mal? Encerram-se neste trabalho?

Em alguns casos, sim. Até porque a palavra "teoria" às vezes causa confusão para algumas pessoas, ao entenderem que se fizerem a recolha, automaticamente está ali a teoria.

Ah!, então temos que mudar o nome disto. Em vez de Teoria dos Cineastas.... Temos que mudar o nome...

Isso é importante estar numa entrevista. Estar registrado.

Manuela, eu achei ótimo aquele nome que tu deste, "Teoria dos pesquisadores a partir dos cineastas".

“Teoria do cinema a partir dos cineastas": ficaria melhor assim? Então mudamos o nome (risos). Assim escusamos de ficar com dúvidas, não é? 
O filme-ensaio é algo que tem me interessado bastante porque parece ser o suporte escolhido por muitos dos cineastas que querem usar seus filmes para teorizar, para propor teses. Tu achas que o filme-ensaio teria um papel central na Teoria dos Cineastas?

Eu acho que o filme-ensaio é tão importante quanto qualquer outro tipo de filme. A questão está em que estamos a assumir que o filme-ensaio é, logo de partida, reflexivo, sendo uma reflexão sobre o cinema, sobre as próprias imagens... Mas não me parece que possa ser considerado um material mais importante que outros. Ou, é importante para o investigador que está a tratar disso.

Eu não penso que seja mais importante, mas me interessa muito compreender os cineastas que têm uma vontade, uma necessidade de teorizar com os próprios filmes, explicitamente.

Certo, mas disseste uma coisa muito importante aí, que é o "explicitamente". A questão de que essa vontade de teorizar esteja explícita no filme-ensaio não significa dizer que não esteja presente em outros tipos de filme.

Ao contrário dos filmes de uma geração anterior, com teses claramente enunciadas, a gente vê hoje, pelo menos no Brasil, uma onda de filmes contemplativos, com pouco discurso verbal, compreendidos como filmes afetivos justamente porque recusam a vontade de teoria...

Mas esse é outro modo de fazer cinema. 0 cinema começou por ser, de fato, feito sobre uma exterioridade, o enfrentamento da câmara com o lado de lá. E depois a câmera girou, virou-se para o cineasta. Mas a questão é exatamente a mesma que eu dizia: se é esse o tipo de cinema que te interessa, se a intenção é compreender esse tipo de cinema, estão aí 
os próprios filmes e os discursos dos cineastas, discursos interessantes, por exemplo, como os da Petra Costa.

\section{A Manuela trabalha uma unidade curricular chamada Teoria dos Cineastas no Mestrado em Cinema da Universidade da Beira Interior (UBI). Como tem sido a experiência?}

Olha, todos os anos é diferente. Houve um ano em que a única coisa que fizemos o semestre inteiro foi ler o livro do Tarkovski, o "Esculpir o Tempo". Mas este ano de 2019 também foi interessantíssimo. Como é uma disciplina de mestrado, organizamos seminários e, justamente, coloquei a questão do espectador a partir do cineasta. Foram feitos grupos de trabalho a partir de diferentes cineastas e, com as conversas nos grupos, foi-se percebendo que os cineastas se interessam pela figura do espectador como um ser real que possui determinadas capacidades às quais o cineasta se dirige. Um dos trabalhos, inclusive, sobre Patricio Guzmán, foi apresentado agora em 2019 no Encontro da AIM em Santiago de Compostela. As teorias do cinema estabelecidas tendem a olhar para o espectador como uma espécie de invólucro vazio que se vai enchendo com conceitos. Mas os alunos compreenderam que o Patricio Guzmán entende o espectador como um ser que possui uma faculdade fundamental que é a memória. E é a essa memória que o cineasta se dirige. Portanto, é possível vermos diferentes concepções de espectador para diferentes cineastas e a partir daí construirmos outra teoria do cinema. Mais uma vez, ter como primeiro passo a recolha e, a seguir, um segundo passo propositivo. E este ano acho que foi um dos mais interessantes, de fato essa disciplina correu bastante bem, acho eu.

As propostas que chegam ao ST Teoria dos Cineastas da Socine são normalmente oriundas de pesquisas que se dedicam a realizadores com perfil autoral. Mas nós também recebemos proposições que destoam, como o trabalho sobre o making of como ato de teoria, ou aquele sobre a 
teoria de cineastas indígenas. Ambos compõem este Dossiê da InTexto. Enfim, quaisquer filmes são passíveis de investigação nessa abordagem?

Eu acho que sim. Qualquer filme, qualquer cineasta, por mais que nós o entendamos como comercial. Eu acho que é importantíssimo compreendermos o cinema atual, é o cinema que existe, é o cinema que é feito. Por exemplo, eu estive a ler sobre cinema indígena e encontrei algo que achei fabuloso que é o fato de que o cineasta indígena não diz "eu sou cineasta", diz "eu estou cineasta". Isso é fabuloso, é outra maneira de pensar o cinema. Isso nunca passaria pela minha cabeça, e acho que de ninguém dentro da academia, se não fosse ouvido a partir de alguém que faz filmes. Absolutamente estrondoso. Mais uma vez, a teoria do cinema só tem a ganhar ao colocar-se ao lado disso, de ver a partir daí o que é que pode compreender sobre o cinema.

Está se construindo uma teoria da Teoria dos Cineastas? Quer dizer, falase em abordagem, mas caminha-se para uma teoria no sentido estrito?

Eu acho que não. Há um paradigma, ou seja, um modo de agir, de se compreender o cinema estando mais próximo do cineasta. E eu acho que vocês no Seminário Temático da Socine têm feito esse trabalho. Ou seja, tudo o que vocês têm estado a apresentar no seminário temático configura um modo de estar na academia e um modo de fazer investigação.

\section{Referências bibliográficas}

AUMONT, Jacques. As teorias dos cineastas. Campinas: Papirus, 2004.

AUMONT, Jacques. Pode um filme ser um ato de teoria? Revista Educação e Realidade, Porto Alegre, v. 1, n. 33, p. 21-34, jan/jun, 2008.

PENAFRIA, Manuela. 0 paradigma do documentário: António Campos, Cineasta. Covilhã: Labcom, 2009. 
PENAFRIA, Manuela (ed.). Tradição e Reflexões: contributos para a teoria e a estética do documentário. Covilhã: Labcom, 2011.

PENAFRIA, Manuela; BAGGIO, Eduardo; GRAÇA, André Rui; ARAÚJO, Denize Correa. Observações sobre a "Teoria dos Cineastas"- nota dos editores. In: PENAFRIA, Manuela; BAGGIO, Eduardo; GRAÇA, André Rui; ARAÚJO, Denize Correa (eds.).

Revisitar a Teoria do Cinema: Teoria dos cineastas, v.3. COVILHÃ: Labcom, 2017.

PENAFRIA, Manuela; BAGGIO, Eduardo; GRAÇA, André Rui; ARAÚJO, Denize (eds.). Ver, ouvir e ler os cineastas: Teoria dos cineastas, v.1. COVILHÃ: Labcom, 2016.

PENAFRIA, Manuela; Vilão, Henrique; RAMIRO, Tiago. 0 ato de criação cinematográfica e a "Teoria dos Cineastas". In: PENAFRIA, Manuela; BAGGIO, Eduardo; GRAÇA, André Rui; ARAÚJO, Denize (eds.). Propostas para a teoria do cinema: Teoria dos cineastas, v.2. COVILHÃ: Labcom, 2016. p.93-113

\title{
Making film theory from filmakers - interview with Manuela Penafria
}

\begin{abstract}
In this interview, the researcher and professor Manuela Penafria (University of Beira Interior, Portugal) exposes the current scenario of the academic field Filmmakers Theory, highlighting the pertinence of renewing film theory from the thoughts expressed in images, sounds and words of filmmakers themselves. Penafria discusses relevant issues for researching and theorizing films, such as the research sources; the difference between words and images in the Filmmakers Theory; the relation of Filmmakers Theory with Jacques Aumont's research on the theories of filmmakers; the concept of spectator that float among filmmakers; and the suspicion that may happen in Academy regarding Filmmakers Theory.
\end{abstract}

\section{Keywords}

Filmmakers Theory. Film theory. Spectator. Jacques Aumont. Essay film.

Recebido em 30/10/2019

Aceito em 31/10/2019 